\title{
Investigating the Effects of Phenytoin, Phenobarbital, Topi- ramate, Carbamazepine and Sodium Valproate on the Neu- rotransmitter Speed in Treated Seizure Children
}

\author{
Farzad Ahmadabadi ${ }^{1}$, Ghasem Fattahzadeh ${ }^{2}$, Abolfazl Atalu ${ }^{2 *}$ and Pooya Badihi ${ }^{3}$ \\ ${ }^{1}$ Department of Pediatrics, School of Medicine, Ardabil University of Medical Sciences, Ardabil, Iran \\ ${ }^{2}$ Department of Neurology, School of Medicine, Ardabil University of Medical Sciences, Ardabil, Iran \\ ${ }^{3}$ School of Medicine, Ardabil University of Medical Sciences, Ardabil, Iran
}

*Corresponding author: Dr. Abolfazl Atalu, Department of Neurology, School of Medicine, Ardabil University of Medical Sciences, Ardabil, Iran

\begin{abstract}
Anticonvulsants such as phenytoin, phenobarbital, topiramate, carbamazepine and valproate due to their beneficial effects and economic benefits in compare to new drugs are used more but these drugs are not harmless and sometimes had dangerous, safe and reversible side effects. Reduction of the nervous conduction velocity (NCV) is the common side effect of these drugs and it is of clinically importance if it is severe especially in treated children. Therefore, it is necessary to evaluate and compare the effect of each drug on NCV. The aim of this study was to investigate the effects of antiepileptic drugs on NCV. In this quasi-experimental study, 125 children with seizure were randomly selected and divided into six equal size groups which received phenytoin, phenobarbital, topiramate, valproate, carbamazepine and one group as control which no received anti-epileptic drug. Sensory and motor neural conduction velocity were measured and recorded for all children in groups. Collected data were analyzed by statistical methods in SPSS version 19. All of anticonvulsants were reduced the NCV in children but among all drugs, phenobarbital and phenytoin had the least and most impact on the NCV. The changes in NCV were not related to the age and gender of children. Results showed that the anticonvulsants had similar impact on NCV in generally but future studies are recommended by considering the other effective variables on response to drug.
\end{abstract}

\section{Keywords}

Seizure, Anticonvulsants, Nerve conduction velocity (NCV), Epilepsy

\section{Introduction}

About one percent of the world's population had epilepsy. Epilepsy attacks are the second most common neurological disorder after stroke. Today standard treatments have managed to control nearly $80 \%$ of patients. Seizures are short term episodes as a result of abnormal discharge of brain neurons. Various causes such as infection, neoplasm or trauma may be involved in these attacks. Epilepsy is one of the most common diagnoses seen by pediatric neurologists. One percent to two percent of the pediatric population has epilepsy [1]. Almost $4-10 \%$ of children experience at least one seizure. The prevalence of epilepsy in children is about $1-2 \%$. The goal of treatment in children is to maintain optimal functional status. About in $60 \%$ of children, the seizure was controlled by using an appropriate primary drug and the results are satisfactory. We know that while $80 \%$ of people with epilepsy live in low- and middle-income countries, most of them do not have access to treatment [2]. Seizure is one of the most common diseases in children age group which was controlled by the availability of anticonvulsants, and due to the impact of anticonvulsants which act through the action on the membrane potential, it seems that these medications can affect the NCV [3-6]. Of course, in the poisoning with some medications such as phenytoin, the NCV has decreased. On the other one, one of the effective factors on the NCV was ambient temperature while

Citation: Ahmadabadif F, Fattahzadeh G, Atalu A, Badihi P (2019) Investigating the Effects of Phenytoin, Phenobarbital, Topiramate, Carbamazepine and Sodium Valproate on the Neurotransmitter Speed in Treated Seizure Children. Int J Neurol Neurother 6:093. doi.org/10.23937/2378-3001/1410093 Accepted: December 16, 2019: Published: December 18, 2019

Copyright: (C) 2019 Ahmadabadif F, et al. This is an open-access article distributed under the terms of the Creative Commons Attribution License, which permits unrestricted use, distribution, and reproduction in any medium, provided the original author and source are credited. 
some anticonvulsants can increase fever in body [7-10]. Also, consumers of anticonvulsants in neurological examinations show declining deep reflexes [11].

Anticonvulsants such as phenytoin, phenobarbital, topiramate, carbamazepine and valproate due to their beneficial effects and economic benefits in compare to new drugs are used more but these drugs are not harmless and sometimes had dangerous, safe and reversible side effects. Reduction of the nervous conduction velocity (NCV) is the common side effect of these drugs and it is of clinically importance if it is severe especially in children and need for more attention of physician in clinically using of these drugs. The aim of this study was to investigate the effects of antiepileptic drugs on NCV.

\section{Materials and Methods}

This was a quasi-experimental study. In this study, children aged 2-15 years with one of generalized or partial seizures requiring anticonvulsant drugs (Phenytoin, phenobarbital, Topiramate, carbamazepine, sodium valproate) selected and randomly divided into 5 groups each with 25 patients and each group received a drug. We also selected a control group without any drug use. Children were excluded from the study if they had any disruptive factors which affect NCV. At base line an NCV was performed for all groups. In this study the NCV were measured in the upper limbs in the median and ulna nerves and in the lower limbs in Peroneal and sural nerves by the EMG-NCV, Micromed device (made in Italy) and 6 months later these measurements was performed again and the necessary data were collected. After collecting NCV information along with age, sex and type of drug, data were analyzed by statistical methods in SPSS version 19.

\section{Ethical approve}

This study ethical approves by ethical committee of Ardabil University of Medical Sciences and registered by code REC.ARUMS.1397.675. In this study parents of children were informed and the consent form was completed for them.

\section{Results}

The average age of children was $5.5 \pm 2.9$ years in range of 2 to 11 . Of all children, $68(45.4 \%)$ were boy and $82(55.6 \%)$ were girls. All of used drugs compared to the control group, significantly reduced sensory and motor NCV of upper and lower limbs nerves.

The phenytoin as an anti-seizure drug compared to the control group significantly reduced the motor and sensory NCV in the upper and lower limbs for nerves Median, Sural and Peroneal but the difference between phenytoin at baseline and control in Ulnar nerve wasn't significant (Table 1).

The phenobarbital as an anti-seizure drug compared to the control group significantly reduced the motor and sensory NCV in the upper and lower limbs for nerves Median, Sural and Peroneal but the difference between phenobarbital at baseline and control in Ulnar nerve wasn't significant (Table 2).

The topiramate as an anti-seizure drug compared to the control group significantly reduced the motor and sensory NCV in the upper and lower limbs for nerves Median, Sural, Ulnar and Peroneal (Table 3).

The sodium-valproate as an anti-seizure drug compared to the control group significantly reduced the motor and sensory NCV in the upper and lower limbs for nerves Median, Sural, Ulnar and Peroneal (Table 4).

Table 1: Compare the mean of NCV in treated patients with phenytoin by type of nerve.

\begin{tabular}{|c|c|c|c|}
\hline Type of nerves & Drugs & Mean & $P$ - value \\
\hline \multirow[t]{2}{*}{ Median } & Phenytoin in Baseline & 52 & \multirow[t]{2}{*}{0.009} \\
\hline & Control & 58.7 & \\
\hline \multirow[t]{2}{*}{ Median } & Phenytoin in baseline & 52 & \multirow[t]{2}{*}{0.016} \\
\hline & Phenytoin 6 month late & 51.6 & \\
\hline \multirow[t]{2}{*}{ Ulnar } & Phenytoin in Baseline & 51.2 & \multirow[t]{2}{*}{0.058} \\
\hline & Control & 50.8 & \\
\hline \multirow[t]{2}{*}{ Ulnar } & Phenytoin in baseline & 51.2 & \multirow[t]{2}{*}{0.011} \\
\hline & Phenytoin 6 month late & 50.6 & \\
\hline \multirow[t]{2}{*}{ Sural } & Phenytoin in Baseline & 47.7 & \multirow[t]{2}{*}{0.002} \\
\hline & Control & 50.6 & \\
\hline \multirow[t]{2}{*}{ Sural } & Phenytoin in baseline & 47.7 & \multirow[t]{2}{*}{0.026} \\
\hline & Phenytoin 6 month late & 47.2 & \\
\hline \multirow[t]{2}{*}{ Peroneal } & Phenytoin in Baseline & 43.8 & \multirow[t]{2}{*}{0.002} \\
\hline & Control & 46.4 & \\
\hline \multirow[t]{2}{*}{ Peroneal } & Phenytoin in baseline & 43.8 & \multirow[t]{2}{*}{0.009} \\
\hline & Phenytoin 6 month late & 42.9 & \\
\hline
\end{tabular}


Table 2: Compare the mean of NCV in treated patients with phenobarbital by type of nerves.

\begin{tabular}{|c|c|c|c|}
\hline Type of nerves & Drugs & Mean & $P$ - value \\
\hline \multirow[t]{2}{*}{ Median } & Phenobarbital in baseline & 56 & \multirow[t]{2}{*}{0.038} \\
\hline & Control & 58.7 & \\
\hline \multirow[t]{2}{*}{ Median } & phenobarbital in baseline & 56 & \multirow[t]{2}{*}{0.065} \\
\hline & phenobarbital six month late & 55.4 & \\
\hline \multirow[t]{2}{*}{ Ulnar } & phenobarbital in baseline & 54.2 & \multirow[t]{2}{*}{0.06} \\
\hline & Control & 50.8 & \\
\hline \multirow[t]{2}{*}{ Ulnar } & phenobarbital in baseline & 54.2 & \multirow[t]{2}{*}{0.057} \\
\hline & Phenobarbital six month late & 53.2 & \\
\hline \multirow[t]{2}{*}{ Sural } & phenobarbital in Baseline & 45.2 & \multirow[t]{2}{*}{0.001} \\
\hline & Control & 50.6 & \\
\hline \multirow[t]{2}{*}{ Sural } & phenobarbital in baseline & 45.2 & \multirow[t]{2}{*}{0.06} \\
\hline & Phenobarbital six month late & 43.8 & \\
\hline \multirow[t]{2}{*}{ Peroneal } & phenobarbital in baseline & 42.8 & \multirow[t]{2}{*}{0.011} \\
\hline & Control & 46.4 & \\
\hline \multirow[t]{2}{*}{ Peroneal } & phenobarbital in baseline & 42.8 & \multirow[t]{2}{*}{0.053} \\
\hline & Phenobarbital six month late & 41.2 & \\
\hline
\end{tabular}

Table 3: Compare the mean of NCV in treated patients with topiramate by type of nerves.

\begin{tabular}{|c|c|c|c|}
\hline Type of nerves & Drugs & Mean & $P$ - value \\
\hline \multirow[t]{2}{*}{ Median } & topiramate in baseline & 52.3 & \multirow[t]{2}{*}{0.003} \\
\hline & Control & 58.7 & \\
\hline \multirow[t]{2}{*}{ Median } & topiramate in baseline & 52.3 & \multirow[t]{2}{*}{0.053} \\
\hline & topiramate six month late & 52.4 & \\
\hline \multirow[t]{2}{*}{ Ulnar } & topiramate in baseline & 50.2 & \multirow[t]{2}{*}{0.0024} \\
\hline & Control & 50.8 & \\
\hline \multirow[t]{2}{*}{ Ulnar } & topiramate in baseline & 50.2 & \multirow[t]{2}{*}{0.061} \\
\hline & topiramate six month late & 50.1 & \\
\hline \multirow[t]{2}{*}{ Sural } & topiramate in Baseline & 46.7 & \multirow[t]{2}{*}{0.003} \\
\hline & Control & 50.6 & \\
\hline \multirow[t]{2}{*}{ Sural } & topiramate in baseline & 46.7 & \multirow[t]{2}{*}{0.298} \\
\hline & topiramate six month late & 46.2 & \\
\hline \multirow[t]{2}{*}{ Peroneal } & topiramate in baseline & 43.8 & \multirow[t]{2}{*}{0.0051} \\
\hline & Control & 46.4 & \\
\hline \multirow[t]{2}{*}{ Peroneal } & topiramate in baseline & 43.8 & \multirow[t]{2}{*}{0.13} \\
\hline & topiramate six month late & 43.02 & \\
\hline
\end{tabular}

Table 4: Compare the mean of NCV in treated patients with sodium valproate by type of nerves.

\begin{tabular}{|l|l|l|l|}
\hline Type of nerves & Drugs & Mean & P -value \\
\hline Median & sodium valproate in baseline & 53.4 & 0.003 \\
\hline & Control & 58.7 & 0.072 \\
\hline Median & sodium valproate in baseline & 53.4 & \\
\cline { 2 - 2 } & sodium valproate six month late & 53.3 & 0.0002 \\
\hline Ulnar & sodium valproate in baseline & 50.1 & \\
\cline { 2 - 3 } & Control & 50.8 & 0.068 \\
\hline
\end{tabular}




\begin{tabular}{|c|c|c|c|}
\hline \multirow[t]{2}{*}{ Sural } & sodium valproate in Baseline & 47.5 & \multirow[t]{2}{*}{0.004} \\
\hline & Control & 50.6 & \\
\hline \multirow[t]{2}{*}{ Sural } & sodium valproate in baseline & 47.5 & \multirow[t]{2}{*}{0.1} \\
\hline & sodium valproate six month late & 47.8 & \\
\hline \multirow[t]{2}{*}{ Peroneal } & sodium valproate in baseline & 46.8 & \multirow[t]{2}{*}{0.046} \\
\hline & Control & 46.4 & \\
\hline \multirow[t]{2}{*}{ Peroneal } & sodium valproate in baseline & 46.8 & \multirow[t]{2}{*}{0.095} \\
\hline & sodium valproate six month late & 46.75 & \\
\hline
\end{tabular}

Table 5: Compare the mean of NCV in treated patients with Carbamazepine by type of nerves.

\begin{tabular}{|c|c|c|c|}
\hline Type of nerves & Drugs & Mean & $P$ - value \\
\hline \multirow[t]{2}{*}{ Median } & Carbamazepine in baseline & 52.4 & \multirow[t]{2}{*}{0.004} \\
\hline & Control & 58.7 & \\
\hline \multirow[t]{2}{*}{ Median } & Carbamazepine in baseline & 52.4 & \multirow[t]{2}{*}{0.028} \\
\hline & Carbamazepine six month late & 50.6 & \\
\hline \multirow[t]{2}{*}{ Ulnar } & Carbamazepine in baseline & 50.6 & \multirow[t]{2}{*}{0.0039} \\
\hline & Control & 50.8 & \\
\hline \multirow[t]{2}{*}{ Ulnar } & Carbamazepine in baseline & 50.6 & \multirow[t]{2}{*}{0.041} \\
\hline & Carbamazepine six month late & 48.7 & \\
\hline \multirow[t]{2}{*}{ Sural } & Carbamazepine in Baseline & 48.1 & \multirow[t]{2}{*}{0.006} \\
\hline & Control & 50.6 & \\
\hline \multirow[t]{2}{*}{ Sural } & Carbamazepine in baseline & 50.6 & \multirow[t]{2}{*}{0.03} \\
\hline & Carbamazepine six month late & 48.04 & \\
\hline \multirow[t]{2}{*}{ Peroneal } & Carbamazepine in baseline & 46.5 & \multirow[t]{2}{*}{0.0286} \\
\hline & Control & 46.4 & \\
\hline \multirow[t]{2}{*}{ Peroneal } & Carbamazepine in baseline & 46.5 & \multirow[t]{2}{*}{0.037} \\
\hline & Carbamazepine six month late & 46.3 & \\
\hline
\end{tabular}

The carbamazepine as an anti-seizure drug compared to the control group significantly reduced the motor and sensory NCV in the upper and lower limbs for nerves Median, Sural, Ulnar and Peroneal (Table 5).

The effect of anticonvulsants on the motor and sensory NCV of the upper and lower limbs was not related to the gender and age of children.

By comparing the effect of phenytoin and phenobarbital on NCV, we seen that in the median nerve phenytoin significantly reduced the NCV more than phenobarbital. Comparing the effect of phenobarbital and topiramate on NCV, we see that topiramate significantly reduced the NCV in the median nerve more than phenobarbital. Comparing the effect of phenobarbital and valproate on NCV, we see that valproate sodium significantly reduced the NCV in median nerve more than phenobarbital. Comparing the effect of phenobarbital and carbamazepine on NCV we see that carbamazepine significantly reduced the NCV in the median nerve more than phenobarbital.

\section{Discussion}

In a similar study in 1990, Krause, et al. suggested that anticonvulsants reduced the NCV in the median and peroneal nerves [3]. A study by Danner, et al. found that carbamazepine as an anti-seizure drug more than phenytoin reduced the NCV which was similar to our study results [12]. According to the results of Freeman, et al. research on the subject of polyneuropathy treatment, the mean of decrease in NCV for placebo was higher than that of topiramate. Secondary measurements showed that the NCV was not reduced for treated patients with topiramate [13]. Swift, et al. showed that there was no relationship between phenobarbital or phenytoin levels in blood and the duration of their use and abnormality of electrical findings as well as environmental neuropathy [14]. According to research by Chokroverty, et al. the NCV in the posterior tibial nerve was significantly reduced in patients who had been treated with phenytoin for more than 10 years or those who had a drug level of more than $20 \mathrm{mug} / \mathrm{ml}$ in their blood [15]. In a study by Danner, et al. the results show that carbamazepine reduce the NCV after 4 weeks treatment [16]. The result of Danner, et al. study showed a significant decrease in NCV in seizure patients who receiving anticonvulsants compared to the control group which was similar to our study results [17]. In research by Castro, et al. the NCV in patients receiving anticonvulsants is significantly reduced compared to the control group 
(healthy people) [18]. According to research by Ramirez, et al. long term use of phenytoin causes the destruction of nerve cells and their demyelination and reduces NCV and 16 months after the drug cut, the nerve cells are restored [19]. Studies by Traccis, et al. showed that long term treatment with carbamazepine reduced the sensory and motor NCV of the environmental nerves [20]. Zebrowska, et al. concluded in their research that by using 300-400 mg of phenytoin every day, the NCV in the environmental nerves will not decrease [21]. The present study showed that all of the anticonvulsants used in this study reduced the motor and sensory NCV of the upper and lower limbs. This difference was statistically significant for each drug compared to the control group. About Phenytoin and carbamazepine results showed that the difference in NCV in baseline and six months late was significant.

Geraldini and Taylor in their study showed that gender was not related to the effect of anticonvulsant drugs on NCV in patients [5,22]. Krause, et al. in their study stated that the gender of patients was ineffective in the motor and sensory NCV of median and perineal nerves but the NCV in the median nerve in men was lower than women [3]. Boylu and Shorvon and Encinoza similar to our study, in their research stated that the gender of the patients did not affect the NCV $[4,6,23]$.

The findings of this study were in line with other studies which showed that the gender of patients did not affect the motor and sensory NCV in patients treated with anticonvulsants. Boylu and Shorvon and Encinoza in their research showed that age of the patients did not affect the NCV $[4,6,23]$. The results of this study similar to other studies, showed that there was no relation between the age of patients and their sensory and motor NCV reduces when taking anticonvulsants.

Danner, et al. found that anticonvulsants reduce NCV but of them carbamazepine reduces NCV more than phenytoin [12]. Swift, et al. in their studies showed that there is no relation between the level of phenobarbital or phenytoin in blood and the duration of their use and the abnormality of electrical findings as well as environmental neuropathy [14]. The results of Mervaala, et al. showed that the effects of phenytoin and carbamazepine on the NCV were similar to others. The effect of sodium valproate on reducing NCV is less than the other two drugs [24]. Zafeiridou, et al. in their study showed that phenytoin even at below concentrations has neurological complications [25]. Hamed, et al. showed that among the anti-seizure drugs, phenytoin had the most complications of neuropathy. environmental neuropathy is almost reported in carbamazepine treatment and environmental neuropathy also common in the administration of other anticonvulsants such as sodium valproate and topiramate [26]. Uemura, et al. Stated that the rate of decreased NCV is higher in phenytoin than carbamazepine [27]. According to Ay, et al. study, both carbamazepine and valproate sodium cause environmental neuropathy and there was no significant difference in the side effects of neuropathy between two drugs [28]. In this study similar to previous studies, phenobarbital decreases the rate of NCV less than other drugs and phenytoin more than other drugs reduced the NCV. But differences in the results of the effects of carbamazepine can be due to the variability of its blood level and previous studies have been carried out to evaluate the blood levels of drugs and starting an anticonvulsant medication as a first line of treatment may also be involved. Also the racial and age differences in response to drugs should not be over looked and this topic due to neurological complications especially in children is very important.

\section{Conclusions}

All of the anticonvulsants used in the study, reduced the motor and sensory NCV of the upper and lower extremities of the nerves. The gender of patients did not affect the sensory and motor NCV of the seizure patients treated with anticonvulsants. There was no significant correlation between the age of patients and their sensory NCV when taking anticonvulsant drugs. Anticonvulsant medications were similar in the reduction of NCV but among them phenobarbital was less effective than other drugs and phenytoin reduced NCV more than others. It is suggested that studies be conducted on the basis of the blood levels of drugs in the future.

\section{Conflict of Interest}

None-declared.

\section{Financially Support}

This study results of a Medical Doctoral thesis which approved by Ardabil University of Medical Science and author would like to thanks all patients participated in the study.

\section{References}

1. Knupp K, Koh S, Park K (2012) Pediatric Epilepsy. Neurol Clin Pract 2: 40-47.

2. WHO (2019) Epilepsy: A public health imperative.

3. Krause KH, Berlit P (1990) Nerve conduction velocity in patients under long-term treatment with antiepileptic drugs. Electromyography and Clinical Neurophysiology 30: 61-64.

4. Shorvon S, Reynolds E (1982) Anticonvulsant peripheral neuropathy: A clinical and electrophysiological study of patients on single drug treatment with phenytoin, carbamazepine or barbiturates. Journal of Neurology, Neurosurgery \& Psychiatry 45: 620-626.

5. Geraldini C, Faedda MT, Sideri G (1984) Anticonvulsant therapy and its possible consequences on peripheral nervous system: A neurographic study. Epilepsia 25: 502-505.

6. Boylu E, Domaç F, Mısırlı H, Senol M, Saraçoğlu M (2010) 
Effects of the antiepileptic drugs on peripheral nerve function. Acta Neurologica Scandinavica 121: 7-10.

7. Mochizuki Y, Suyehiro Y, Tanizawa A, Ohkubo H, Motomura $T$ (1981) Peripheral neuropathy in children on long-term phenytoin therapy. Brain and Development 3: 375-383.

8. So EL, Penry JK (1981) Adverse effects of phenytoin on peripheral nerves and neuromuscular junction: A review. Epilepsia 22: 467-473.

9. Moglia A, Tartara A, Arrigo A, Poggi P, Scelsi M, et al (1981) Chronic treatment with phenytoin in rats: Effects of peripheral nervous system. II Farmaco edizionescientifica 36: 419-424.

10. Yuasa J, Kishi R, Harabuchi I, Eguchi T, Arata Y, et al. (1996) Effects of age and skin temperature on peripheral nerve conduction velocity--a basic study for nerve conduction velocity measurement in worksite. Sangyo eiseigaku zasshi 38: 158-164.

11. Awang MS, Abdullah JM, Abdullah MR, Tahir A, Tharakan J, et al. (2007) Nerve conduction study of healthy Asian Malays: The influence of age on median, ulnar, and sural nerves. Medical Science Monitor 13: CR330-CR332.

12. Danner R, Lang H, Yale C (1984) Prospective neurometric studies during the beginning of carbamazepine and phenytoin therapy. Acta Neurologica Scandinavica 69: 207-217.

13. Freeman R, Mclntosh K, Vijapurkar U, Thienel U (2007) Topiramate and physiologic measures of nerve function in polyneuropathy. Acta Neurologica Scandinavica 115: 222231.

14. Swift TR, Gross JA, Ward LC, Crout BO (1981) Peripheral neuropathy in epileptic patients. Neurology 31: 826-831.

15. Chokroverty S, Sayeed Z (1975) Motor nerve conduction study in patients on diphenylhydantoin therapy. Journal of Neurology, Neurosurgery \& Psychiatry 38: 1235-1239.

16. Danner R, Partanen J, Keränen T, Reinikainen K, Hallikainen $\mathrm{E}$, et al. (1988) Comparison of the effects of carbamazepine and oxcarbazepine on peripheral nerve conduction. Epilepsy Research 2: 272-275.

17. Danner R, Partanen V, Riekkinen P (1981) Chronic anticonvulsive therapy, peripheral nerve conduction velocity, and EMG. Epilepsia 22: 675-687.

18. Castro JH, Acosta ML, Sica RE, Guercio N (1972) Sensory and motor nerve conduction velocity in long-term diphenylhydantoin therapy. Arquivos de neuro-psiquiatria 30: 215220.

19. Ramirez JA, Mendell JR, Warmolts JR, Griggs RC (1982) Phenytoin neuropathy: structural changes in the sural nerve. Annals of Neurology 19: 162-167.

20. Traccis S, Monaco F, Sechi G, Moglia A, Mutani R (1983) Long-term therapy with carbamazepine: Effects on nerve conduction velocity. European Neurology 22: 410-416.

21. Zebrowska-Szymusik M (1978) Effect of phenytoin on peripheral motor neurons. Neurologiai Neurochirurgia Polska 12: $427-334$

22. Taylor JW, Murphy MJ, Rivey MP (1985) Clinical and electrophysiologic evaluation of peripheral nerve function in chronic phenytoin therapy. Epilepsia 26: 416-420.

23. Encinoza O (1974) Nerve Conduction Velocity in Patients on Long-Term Diphenylhydantoin Therapy. Epilepsia 15: 147-154.

24. Mervaala E, Keränen T, Tiihonen P, Riekkinen P (1987) The effects of carbamazepine and sodium valproate on SEPs and BAEPs. Electroencephalography and Clinical Neurophysiology/Evoked Potentials Section 68: 475-478.

25. Zafeiridou G, Spilioti M, Kagiava A, Krikonis K, Kosmidis EK, et al. (2016) Differential effects of lacosamide, phenytoin and topiramate on peripheral nerve excitability: An ex vivo electrophysiological study. Neurotoxicology 52: 57-63.

26. Hamed SA (2017) Topiramate induced peripheral neuropathy: A case report and review of literature. World Journal of Clinical Cases 5: 446.

27. Uemura Y, Fujita T, Ohtsubo S, Hirakawa N, Sakaguchi Y, et al. (2014) Effects of various antiepileptics used to alleviate neuropathic pain on compound action potential in frog sciatic nerves: Comparison with those of local anesthetics. BioMed Research International 2014.

28. Ay H, Ethemoğlu Ö (2017) An investigation on the effects of carbamazepine and sodium valproate on neuromuscular transmission. Acta Neurologica Belgica 1-4. 